\title{
Novedad de la espiritualidad conciliar Novedad enraizada en el evangelio
}

\author{
Pedro Trigo \\ Caracas (Venezuela)
}

La importancia del tema radica en que el Vaticano II no se limita a poner algunos énfasis que juzga oportunos en la espiritualidad que se venía desarrollando, sino que, yendo a las raíces y por fidelidad al evangelio de nuestro Señor Jesucristo, y escuchando a su Espíritu, que alienta en la historia, logra vislumbrar una auténtica novedad. Quiero insistir en que la novedad es real respecto de toda la tradición, al menos tal como la conozco; pero, no menos, en que esta novedad de perspectiva y contenido es novedad en fidelidad, es decir, no solo en fidelidad a la actualidad del Espíritu, sino, indivisamente, en fidelidad a Jesús de Nazaret en nuestro hoy. Con esto estamos queriendo decir que la novedad plasma en nuestra situación las intuiciones fundamentales de Jesús, su mentalidad, sus actitudes básicas o, dicho de un modo más global, su misión en el mundo.

\section{1. ¿Cabe la novedad en el cristianismo?}

Si Jesús es el revelador absoluto del Padre y además lo es humanado, es obvio que para un cristiano no cabe otro evangelio que el de Jesucristo ${ }^{1}$. Para un cristiano no hay novedad respecto de Jesús. En caso contrario, Jesús no sería el revelador escatológico. En ese sentido, la Iglesia rechazó la propuesta de Joaquín de Fiore, que sostenía que ya estamos en la era del Espíritu, que es superior a la del Hijo, como esta lo fue respecto de la del Padre ${ }^{2}$. Así, pues, cuando sostenemos una novedad en el cristianismo, no afirmamos que sea nueva respecto al evangelio, sino respecto a lo que los cristianos hemos descubierto del evangelio hasta hoy. El que la Palabra supere infinitamente a la Iglesia, aunque la Iglesia

1. Gal 1,$8 ; c f . D V 4_{2}$.

2. H. de Lubac, La posteridad espiritual de Joaquín de Fiore I y II (Madrid: Encuentro, 1989 y 2011). 
nazca de la Palabra y sea su hija legítima, es, pues, el presupuesto de nuestra propuesta $^{3}$.

Por eso, la posibilidad de que se dé una auténtica novedad y que, sin embargo, esté arraigada en los evangelios presupone que estos no están completamente desvelados. Más aún, se precisará toda la historia para que se desvelen y probablemente nunca se desvelarán del todo en esta historia ${ }^{4}$.

$\mathrm{Si}$ por el contrario, se concibe que el cristianismo sea reducible a proporciones doctrinales y que esas proposiciones las posea la Iglesia desde siempre y que su labor sea, precisamente, conservar y transmitir ese depósito, no es posible que se den novedades auténticas. Ahora bien, en este caso, la Iglesia señorearía a la Palabra, en vez de estar a su servicio ${ }^{5}$. La Iglesia sería no sacramento de salvación, como sostuvo el concilio, sino la institución portadora de la salvación, que era la opinión mayoritaria en la Iglesia preconciliar, de manera que "fuera de la Iglesia no hay salvación".

Sin embargo, no es así porque "la Palabra se hizo carne" (Jn 1,14), es decir, humanidad, historia, y la carne de la Palabra, permaneciendo en la Iglesia, la supera infinitamente. Así, pues, hay implicación mutua, pero no adecuada, entre la Palabra encarnada y la Iglesia, ya que, aunque la Palabra se escucha en la Iglesia y habla por ella, también es escuchada y hablada donde quiere. Por otra parte, no todo lo que habla la Iglesia es Palabra de Dios, porque también existe el pecado en la Iglesia y, por eso, debe reformarse siempre.

Si la revelación personal y personalizadora de Dios fuera reducible a proposiciones doctrinales y práxicas, estaríamos aún en el tiempo de la ley;

3. "La Iglesia, en el correr de los siglos, tiende a la plenitud de la verdad divina hasta que en ella se consumen las palabras de Dios" ( $\left.D V 8_{2}\right)$. "La Esposa del Verbo encarnado, es decir, la Iglesia, enseñada por el Espíritu Santo, se esfuerza por llegar a una inteligencia cada día más profunda de las Sagradas Escrituras, a fin de alimentar incesantemente a sus hijos con las palabras divinas" (DV 23).

4. "El carácter verdaderamente futuro no queda anulado en esta referencia a un evento del pasado, pues aunque ya ha ocurrido en la historia es, sin embargo, un evento de potencialidad infinita por el que Dios mismo, futuro absoluto, se ha autocomunicado al ser humano y al mundo. Por eso el acontecimiento de la revelación no es algo totalmente transparente para la Iglesia, como si la tarea ahora fuera sólo transmitirlo a los otros que no lo conocen o no lo comprenden plenamente. Ese acontecimiento del pasado permanece misterio también para la Iglesia, conserva siempre un más que sobrepasa cualquier comprensión histórica. Por ello la Iglesia no sólo es medio, sino también fruto de salvación, pues ella debe convertirse una y otra vez a partir de ese imperativo contenido en ese evento originante" (Á. Vigueras, "Mediaciones para un método de teología pastoral, a partir de la teología práctica de Karl Rahner", Teología y Vida, 2012, 243).

5. El magisterio "no está por encima de la palabra de Dios, sino a su servicio" $\left(D V 10_{2}\right)$. 
no habríamos alcanzado el tiempo del Reino. Pero Jesús proclama que con su llegada a este mundo como buena nueva escatológica del Padre y con la aceptación por parte del Padre de la confesión que hizo en el Jordán, en nombre de todos, porque nos llevaba a todos en su corazón, ya Dios nos ha aceptado a todos, ya es para siempre nuestro Dios, con el semblante de Padre, y nosotros somos su pueblo y, más concretamente, sus hijos, en el sí de nuestro primogénito y a medida que vayamos dando nuestro sí. Esta necesidad de dar nuestro sí, indispensable en la estructura de la alianza, es la que postula la dimensión histórica del cristianismo y la apertura inacabable de los evangelios.

Es tan distinta la época de las preparaciones a la época de la realización cabal que, para que no se reduzca esta novedad, la época nueva debe labrarse nuevos cauces ${ }^{6}$, no en el sentido de nuevos conceptos y prescripciones, sino en el de un tipo de relación no signado ya por cauces fundamentalmente objetivados, sino por la misma relación, eso sí, una relación en el mismo Espíritu de Jesús de Nazaret y siguiéndolo a él, de manera que lo nuestro sea equivalente a lo que él dijo e hizo, una fidelidad creativa o una creatividad fiel.

Estos cauces se abren camino en la historia y no caben cauces hipostasiados al margen de ella. Pero no cualquier historia, sino siguiendo la historia de Jesús de Nazaret. Por eso, los evangelios son insustituibles, pero también insuficientes. Es indispensable conocer además nuestra situación para tener con ella una relación equivalente a la que tuvo Jesús con la suya. Más aún, los evangelios no se nos abren si no los contemplamos con la actitud de proseguirlos en nuestra situación. Por eso, la lectura discipular de los evangelios solo se puede llevar a cabo desde la búsqueda sincera con una actitud equivalente a la de Jesús. Esta lectura es siempre histórica y exige al que la lleve a cabo asumir su condición histórica.

No obstante, una y otra vez, el cristianismo y, sobre todo, la institución eclesiástica, han recaído en el fariseísmo ${ }^{7}$. Es decir, en la hipostatización de la ley, que incluye como pieza fundamental la disciplina eclesiástica, que al ser tenida como cauce absoluto de la relación con Dios, acaba objetivando y así despersonalizando, a pesar de la intención contraria, la relación con él. Es el fariseísmo cristiano, que renace incesantemente en la Iglesia ${ }^{8}$.

Hay que reconocer que en la Iglesia actual se dan las dos propuestas, que coinciden respectivamente con la de la mayoría y la de la minoría conciliar.

6. "A vino nuevo, odres nuevos" (Mc 2,22).

7. No en el sentido de las desviaciones denunciadas en el capítulo 23 de Mateo, que son más un espejo de la época en que se escribió el evangelio que una ventana abierta a la vida de Jesús, aunque no dejen de serlo, sino en el sentido en el que Pablo dice tener motivos para gloriarse de serlo (Fil 3,4-6).

8. P. Ricoeur, "La simbólica del mal", en Finitud y culpabilidad, pp. 273-302 (Madrid: Trotta, 2004). 
Aunque tal vez hoy se ha invertido el volumen de quienes las sustentan, es decir, que quienes se esfuerzan por vivir la espiritualidad conciliar son minoría en la Iglesia y, más todavía, en la institución eclesiástica.

\section{La declaración Dignitatis humanae: un caso de novedad reconocida}

El concilio se planteó explícitamente el tema de la posibilidad y la pertinencia de la novedad, a propósito de la libertad de conciencia, base de la libertad religiosa. Era patente que la Iglesia, durante muchos siglos y hasta fecha muy reciente, había defendido lo contrario. Había ligado los derechos a la verdad y no a la persona, lo cual traía como consecuencia que la persona que está en el error no tiene derechos.

Frente a esta postura, el documento, que trata sobre la libertad religiosa, se asienta sobre la dignidad humana ${ }^{9}$. Así lo proclama el título y lo establece de entrada, donde reconoce que la conciencia de esa dignidad se ha abierto paso gradualmente en la historia y que el reconocimiento por parte del concilio entraña una auténtica novedad en la Iglesia; novedad afincada, sin embargo, en lo más genuino del evangelio:

La dignidad de la persona humana se hace cada vez más clara en la conciencia de los seres humanos de nuestro tiempo [...] Secundando con diligencia estos anhelos de los espíritus y proponiéndose declarar cuán conformes son con la verdad y con la justicia, este concilio Vaticano II investiga a fondo la sagrada tradición y la doctrina de la Iglesia, de las cuales saca a luz cosas nuevas, coherentes siempre con las antiguas $(D H 1 ; c f .9)$.

Desde esta postura, hay que asentar, como horizonte de fondo, que la dignidad de la persona, fuente de sus derechos, es inalienable y, por tanto, inamisible. Deriva de su condición de imagen de Dios, una condición no consustancial con su constitución, sino don de Dios, ya que imagen no se refiere, ante todo, a un parecido al Creador, por ejemplo, su razón y su libertad, sino, sobre todo, a su destino de entrar en relación personal con é $1^{10}$, a ser oyente de la Palabra ${ }^{11}$.

Esta capacidad de ser potenciado por Dios para poder escuchar su palabra es la que da la medida de su condición histórica. Porque la palabra de Dios no es intrascendente, sino que recrea al ser humano que la escucha y obra a partir de ella. Dios, al hablar al ser humano, manifiesta que tiene fe en él y también la respuesta del ser humano manifiesta su fe en Dios. Esa fe mutua es la fuente más radical de la historicidad del ser humano. Ahora bien, el único clima posible del

9. También el capítulo I de la Gaudium et spes trata de la dignidad humana (12-22).

10. "La Biblia nos enseña que el ser humano ha sido creado 'a imagen de Dios', con capacidad para conocer y amar a su Creador" (GS 12).

11. K. Rahner, Oyente de la palabra (Barcelona: Herder, 1976). 
diálogo es la libertad mutua, una libertad que el propio Dios potencia al liberar la libertad del ser humano para que tenga capacidad para responderle libremente.

Desde este horizonte, el concilio reconoce que la conciencia de cada persona es la última norma de su obrarr2; que existe obligación de esclarecerla, pero que mientras ella perciba algo como bueno, debe hacerlo, aunque objetivamente esté equivocada ${ }^{13}$.

El concilio explica que hay aspectos del evangelio que solo con el avance de los tiempos llegan a esclarecerse, como, por ejemplo, el tema crucial del que trata en ese documento: la dignidad de la persona humana. Pero los que llegan a percibirlos, aunque estén fuera de la Iglesia o no se consideren cristianos, han llegado a ellos como fruto del fermento evangélico: "El fermento evangélico fue actuando durante largo tiempo en la mente de los seres humanos y contribuyó poderosamente a que éstos, en el decurso de los siglos, percibieran con más amplitud la dignidad de su persona" ( $\mathrm{DH} \mathrm{12} 2)$.

El presupuesto de que el evangelio es un fermento que va empapando a la humanidad, o una semilla, la más pequeña, con un poder germinativo absoluto, infinito, que va germinando sin que el ser humano sepa cómo, es una propuesta sustancial en los evangelios. Por eso, el cuarto evangelio pone en boca de Jesús que él tiene todavía muchas cosas que decirles a sus discípulos, pero que ellos no tienen capacidad para recibirlas en ese momento, que luego el Espíritu se las irá aclarando (Jn 16,12-13).

Ahora bien, el Espíritu derramado en la Pascua no se encarna: la Iglesia no es la continuación de la encarnación de Jesús. No hay que entender así el símbolo de que es su cuerpo en la historia. El Espíritu del resucitado se derrama sobre toda carne. Y la Iglesia es sacramento, es decir, el signo vivible e instrumento eficaz de esta acción del Espíritu en toda la humanidad, que supera absolutamente a la Iglesia. Por eso, todo lo que en la historia tiene valor definitivo, tiene que ver con el fermento evangélico, lo haga quien lo haga. Y por eso se puede dar el caso, que de hecho se ha dado, de que la Iglesia no entienda el paso de Dios por la historia, cuyo sujeto son quienes obedecen a su impulso, y de que estigmatice ese actuar sin descubrir en él la marca del Espíritu de su Señor.

Por eso, la Iglesia permanecía aferrada a su alianza con los gobiernos no democráticos (la alianza del trono y del altar, que propició el congreso de Viena

12. "En materia religiosa ni se obligue a nadie a obrar contra su conciencia ni se le impida que actúe conforme a ella en privado y en público, solo o asociado con otros, dentro de los límites debidos" (DC 2; $\left.c f .3_{3}\right)$.

13. Los apóstoles "respetaban a los débiles, aunque estuvieran en el error, manifestando de este modo cómo cada cual dará a Dios cuenta de sí (Rm 14,12), debiendo obedecer entre tanto a su conciencia" $\left(\mathrm{DH} 11_{2}\right)$. 
de 1815), sin reconocer que la libertad religiosa es el presupuesto para recibir el mensaje evangélico, y no solo para abrazar la fe, sino para vivirla, porque la libertad de los hijos de Dios no pertenece solo al santuario de las conciencias, sino que debe manifestarse en el estatuto de las sociedades. De esta infidelidad se hace eco el concilio: "en la vida del pueblo de Dios, peregrino a través de los avatares de la historia humana, se ha dado a veces un comportamiento menos conforme con el espíritu evangélico, e, incluso, contrario a él” ( $\left.\mathrm{DH} 12_{1}\right)$.

Creo que en este caso queda claro que el concilio sostiene que la Iglesia ha ido entendiendo cosas que antes no entendía o que, al comienzo entendió y luego se oscureció su sentido. Y en el ejemplo que estudia, la dignidad humana, se ve que estos puntos no aclarados no son precisamente secundarios. Pero queda igualmente claro que es el fermento evangélico sembrado en la historia humana el que va llevando a los seres humanos hacia la inteligencia concreta y práctica de estas verdades que se refieren al modo de comprender y tratar a la persona humana.

\section{La novedad conciliar: historizar el cristianismo}

Pues bien, en el caso que nos ocupa de la interpretación global de la espiritualidad conciliar, lo que no había llegado a captar la Iglesia antes del concilio es, precisamente, el carácter histórico del ser humano y la relevancia para el quehacer cristiano de este carácter histórico que tienen las acciones, las instituciones y las estructuras, $\mathrm{y}$, sobre todo, los seres humanos que las producen y recrean incesantemente con sus acciones.

Por esta creatividad, tan adecuada a nuestra época y por eso tan oportuna, a la vez que tan arraigada en la tradición que procede de Jesús, y por tanto su actualización, obra del Espíritu, el concilio es para nosotros voz de Dios. Es voluntad de Dios que vivamos el cristianismo desde los cauces conciliares, y esto requiere, ante todo, conocer el concilio y luego recibirlo. Es preciso conocerlo porque, a la velocidad que va nuestro mundo, ambientalmente es un asunto del pasado. Pero como la Iglesia en su conjunto no lo ha recibido o lo ha recibido solo muy incipientemente, tampoco está en el horizonte de la Iglesia ${ }^{14}$. No hacer

14. Que la Iglesia no está en el horizonte del concilio ha quedado patente en la celebración de los cincuenta años, que comenzó en 2012 y culminará en 2015. Las celebraciones oficiales han sido meramente protocolares. Las Iglesias nacionales y las diócesis no lo han celebrado realmente como el acontecimiento que tratan de echar adelante y que pugnan porque las configure. Para empezar, siendo conscientes de que la mayoría de los cristianos ni siquiera lo conocen, no se ha dado a conocer, ni se ha trabajado para recibirlo en esta época, que es distinta de aquella en que aconteció. Algunos especialistas se han aplicado a ello como un tema escolar, como un filón para explotar académicamente. Solo una minoría que se esfuerza por hacerlo vida, porque lo percibe como acontecimiento del Espíritu, se ha referido a él con la densidad de lo real y con la urgencia de descubrir lo que ha sido ocultado y ya 
el esfuerzo sistemático y sostenido de conocerlo es ya no recibirlo, es el modo más radical de no recibirlo, que consiste no en ponerlo en consideración y no aceptarlo, sino en no considerarlo siquiera.

Digamos de una vez en qué consiste esta novedad y qué la ha propiciado. Entonces estaremos en condiciones de fundamentar su legitimidad jesuánica y, por tanto, su condición evangélica: nueva buena, porque contiene salvación; pero no otra, sino actualización de la única buena nueva que tenemos los cristianos, que es la de Jesús de Nazaret. Este es el contenido más denso del aggiornamento, de la puesta al día, que propuso Juan XXIII, cristiano tradicional (no tradicionalista), si los hay, y por eso, abierto en fidelidad al hoy de Dios, en el hoy del mundo.

\subsection{El ser humano es histórico}

Parece superfluo mostrar que el concilio concibe al ser humano históricamente, porque el objetivo que le asignó el papa Juan XXIII fue, precisamente, poner al día a la Iglesia con el mundo. Por esa razón insistió en que un concilio no tenía razón de ser si su objetivo hubiera sido repetir la doctrina. Y por la misma razón, la Constitución sobre la Iglesia en el mundo lleva en su mismo título esta concreción: huius temporis, de este tiempo, y, también por eso, en su segunda parte, la constitución dedica sendos capítulos al matrimonio y a la familia, al progreso cultural, a la vida económica-social, a la vida en la comunidad política y a la comunidad de los pueblos y al fomento de la paz.

Tiene que volver a plantear todos esos aspectos por los cambios tan radicales y acelerados que se sucedían. Así lo asienta desde el comienzo:

El género humano se halla hoy en un período nuevo de su historia caracterizado por cambios profundos y acelerados, que progresivamente se extienden al universo entero. Los provoca el ser humano con su inteligencia y su actividad creadora; pero recaen luego sobre el ser humano, sobre sus juicios y deseos individuales y colectivos, sobre sus modos de pensar y sobre su comportamiento para con las realidades y los seres humanos con los que convive. Tan es así que se puede ya hablar de una verdadera metamorfosis social y cultural, que redunda también sobre la vida religiosa ${ }^{15}$.

Así, pues, el ser humano se transforma a sí mismo al transformar el mundo. La acción histórica es constituyente: no la actividad de un ser ya constituido, sino la acción de hacerse a sí mismo haciendo al mundo.

La novedad, auténtico signo de los tiempos, consiste en hacerse cargo solidariamente de la historia. En esta propuesta queremos destacar tres aspectos. El

olvidado, porque lo ven como necesario para revitalizar el cristianismo en crisis profunda, precisamente por no querer recibirlo.

15. GS $4_{2}$. 
primero es percibir que el ser humano es histórico, es el autor de la historia y se hace a sí mismo al hacer la historia. El ser humano no es una esencia acabada, ya plenamente constituida, que actúa lo que ya es. Por el contrario, el modo humano de ser es ser siendo. Esto significa que ningún acto suyo es capaz de determinarlo completamente porque, aun en el supuesto negado de que un acto suyo tuviera poder para poner su impronta en todas sus facultades y dimensiones, cualificándolas de una manera determinada, la labilidad humana no permite que esa humanidad así constituida se mantenga siempre estable. Lo humano tiende a desmoronarse, lo construido tiende a desestructurarse, como toda la energía tiende a degradarse. Pero además, como, pese a cualquier acto, el ser humano se mantiene abierto, siempre es posible que otro acto suyo transforme lo anteriormente decidido, así como también es posible que otros actos sucesivos lo reafirmen y refuercen.

Este carácter abierto de los seres humanos, que se cualifican a través de sus acciones, aparece en la Biblia de modo paradigmático, en el capítulo 18 del libro de Ezequiel, escrito en el destierro. En el destierro de Babilonia, los israelitas habían caído en cuenta de la infidelidad maciza y progresiva de Israel a la alianza, se sentían víctimas de lo que interpretaban como castigo divino merecido por el proceder de sus antepasados, y, por lo tanto, sin esperanza. En ese estado de postración viene la palabra de Dios con la noticia de que ya no rige más la responsabilidad corporativa y que, por lo tanto, los hijos no cargarán con las consecuencias de lo que hayan hecho sus padres. Cada individuo es responsable individualmente. Pero no solo los descendientes no están encadenados a lo que hayan hecho sus progenitores. Tampoco el individuo lo está a sus propias acciones: una acción puede ser desmentida por la siguiente, tanto en bien como en mal. La consecuencia que saca el capítulo, en consonancia con la situación del pueblo y con lo que el profeta atisba como el querer último de Dios, es que siempre cabe la conversión y que esta apertura obedece a la paciencia de Dios, que no quiere la muerte de nadie, sino que el pecador se convierta y viva. Sin embargo, en rigor, también cabe que el justo se pervierta. Por eso, tenemos que andar siempre con cuidado.

$\mathrm{P}$ ero el concilio da un paso más. El ser humano no solo se hace un ser humano cualitativo a través de sus actos, sino que se hace simplemente humano, ya que el ser humano que es cada uno no nace con papeles prefijados, como pensaba la Iglesia cuando aceptaba la concepción orgánica de la sociedad. Según este pensamiento, que dominó en la Iglesia hasta vísperas del concilio, la sociedad era de desiguales y mutuamente referidos, como lo son los miembros del cuerpo. Así, pues, cada quien nacía con un papel determinado (trabajador, propietario, funcionario, militar, mendigo) y lo que le pedía Dios es que lo representara con 
dignidad y con la mayor excelencia posible ${ }^{16}$. El concilio ha asumido que el hacerse humano no se limita a investir un tipo dado, a representar un libreto ya conocido, sino que entraña inventar el personaje que se quiere ser y dedicarse a serlo, en la medida de su prestancia ${ }^{17}$. El carácter histórico del ser humano no se da al representar papeles sancionados por la tradición y la ley, sino al ir decidiendo quién se quiere ser de modo creativo y autónomo, y al realizarlo, cambiar la configuración de la sociedad.

Esto es posible porque también la sociedad con sus estructuras e instituciones es histórica, es decir, es creada por grupos humanos que buscan objetivos precisos y es transformada por esos u otros grupos para lograr los mismos objetivos con más eficacia o para lograr otros objetivos más deseables. Pero la posibilidad y la amplitud de la movilidad social y antropológica parten de que la naturaleza no es ya para el ser humano algo dado, a lo cual adaptarse optimizándola. La ciencia y la técnica han logrado descifrar los elementos y las estructuras de que consta y se van haciendo progresivamente capaces de reestructurarla e incluso de fabricar elementos nuevos. Naturalmente, el cuerpo humano no ha variado mucho respecto a otros tiempos, pero sí van cambiando aceleradamente los modos de incidir sobre él. Tampoco han cambiado sustancialmente las fuerzas humanas que tejen la vida social, pero sí ha crecido exponencialmente lo que puede hacerse con ellas.

\subsection{Lo relativamente positivo de la acción histórica}

El segundo aspecto consiste en que, después de anotar el hecho de la historicidad del ser humano, el concilio subraya dos aspectos complementarios. El primero consiste en inscribir los hallazgos de la ciencia y la técnica en el designio de Dios, del cual el ser humano participa. Dios creó al ser humano creador. Y estos descubrimientos y las posibilidades plenificadoras y humanizadoras que abren son un ejercicio del carácter creador de la creatura humana, son una realización del designio del Creador al crear a la comunidad humana. Así, pues, todo este proceso no es ajeno a la voluntad de Dios, ni a su concurso

16. La representación paradigmática de esta concepción es El gran teatro del mundo, auto sacramental de Calderón de la Barca, que se supone escrito hacia 1633. La pieza expresa el carácter trascendente del cristianismo respecto de la sociedad estamental, ya que Dios no toma en cuenta la dignidad del papel que desempeña cada uno, sino solo la calidad con cual lo desempeña; pero acepta que cada quien nace con un papel $\mathrm{y}$, por lo tanto, que los papeles sociales son invariables.

17. Nosotros hemos insistido que esa es una de las características de la cultura del barrio: los campesinos que los fundaron vinieron a ellos no solo ni principalmente para encontrar medios de vida, sino para buscarse a sí mismos, y así idearon personajes para llegar a ser personas invistiéndolos (La cultura del barrio, Caracas, Gumilla: 2008, pp. 83-85). 
providente. $\mathrm{Y}$ el verdadero sabio implicado en el proceso con entrega constante y humilde llega a sentir, de un modo u otro, que está cerca de Dios, que colabora con él; y esta cercanía y apertura al misterio lo humanizan (GS 36).

Ahora bien, esta fundamental positividad participa no solo de la apertura de todo lo humano, sino de la indeterminación de lo que es no contenido humano en sentido estricto, sino posibilitación. Vamos a poner un ejemplo. El hecho de que el saneamiento ambiental y la medicina preventiva y curativa, unidas a la estabilidad y la suficiencia derivadas del desarrollo económico, den como resultado que la expectativa de vida se duplique, es en sí positivo. El que la humanidad lo haya logrado con su creatividad, aplicada a la técnica y a la organización social, es, para el concilio, cumplimiento del designio del Creador, y en ese esfuerzo también ha intervenido él. Sin embargo, el que nuestras vidas sean el doble de largas no entraña, de suyo, que sean el doble de humanas. Pueden seguir siendo igualmente humanas, más humanas o menos humanas.

Los hallazgos científicos se componen entre sí (aunque no de modo lineal, ni automático), pero no hay un banco de humanidad cualitativa disponible para cualquiera. Existe influencia en bien y en mal. De la misma manera que hablamos de estructuras y situaciones de pecado, también debiéramos hablar de estructuras que favorecen la vida buena y la humanización de los implicados en ellas. Pero, como dijimos al hablar de la historicidad del ser humano, es cada ser humano el que, en definitiva, se humaniza o deshumaniza con sus decisiones. Por eso, el concilio insiste en que, a pesar de esa relativa positividad, no puede equipararse el desarrollo científico técnico con el desarrollo humano.

Hay que reconocer que no pocos católicos militantes latinoamericanos palparon tanta inhumanidad en sus sociedades, se jugaron tanto en cambiar las condiciones políticas, que hicieran posible la justicia y propiciaran la solidaridad, e incluso, cuando llegaron al poder, valoraron tan positivamente las reformas emprendidas, que sacralizaron su militancia y su proyecto político y, por consiguiente, demonizaron al que había tenido vigencia hasta entonces.

Confundir la relativa positividad con lo escatológico tuvo consecuencias muy serias, tanto en el modo de llevar la lucha política como en la sacralización de su propuesta y del régimen que la expresaba. Al absolutizarse, se proscribió como no cristiana cualquier otra propuesta, se provocó una indebida división entre los cristianos y se anatematizaron los enemigos políticos.

Además, como a la larga se vieron las ambigüedades y aun las negatividades de lo que se instauró y de sus organizaciones, se llegó a la conclusión de que no había que mezclar el cristianismo con la política. Todo por no distinguir entre la dedicación asidua a lo relativamente positivo, es decir, a mejorar las condiciones de vida y relación, y el desarrollo realmente humano, que sí lo es. 


\subsection{Lo definitivo en la acción histórica}

En tercer lugar, el concilio señala que en la medida en que la historia trae desarrollo humano, contiene gérmenes de eternidad, o, dicho de modo más fuerte, es escatológica. Esto significa que lo propiamente humano de lo histórico es, desde otro punto de vista, actuación de la vida de Dios en nosotros, o, en una expresión muy reiterada por el concilio, cumplimiento de la única vocación de la humanidad, que es una vocación trascendente, es decir, divina. Esto lo puede decir el concilio porque contempla la creación como un designio unitario en Jesucristo. Ser humanos es, por él y en él, ser hijos de Dios en el Hijo y hermanos en el Hermano universal. Esta vocación es posibilitada por el Espíritu, que Jesús derramó en la Pascua y que actúa en toda la humanidad.

Todo lo dicho hasta ahora se puede sintetizar en un texto de la Constitución sobre la Iglesia en el mundo actual:

Aunque hay que distinguir cuidadosamente progreso temporal y crecimiento del reino de Cristo, sin embargo, el primero, en cuanto puede contribuir a ordenar mejor la sociedad humana, interesa en gran medida al reino de Dios. Pues los bienes de la dignidad humana, la unión fraterna y la libertad, en una palabra, todos los frutos excelentes de la naturaleza y de nuestro esfuerzo, después de haberlos propagado por la tierra en el Espíritu del Señor y de acuerdo con su mandato, volveremos a encontrarlos libres de toda mancha, iluminados y transfigurados, cuando Cristo entregue al Padre el reino [...]. El reino está ya misteriosamente presente en nuestra tierra: cuando venga el Señor, se consumará su perfección (39).

Así, pues, las acciones humanas, en las que actúa trascendentemente el Espíritu del Señor, producen como fruto bienes definitivos, bienes eternos, verdadera participación de la vida divina. Estos bienes solo consumarán su perfección en la transhistoria; pero, aunque no perfectos, sí son definitivos en esta historia.

Estas expresiones son sumamente elocuentes y realmente nuevas de hasta dónde llegan las acciones humanas. El concilio se atreve a dar nombre a estos frutos espirituales: la dignidad humana, la unión fraterna y la libertad. Se refiere, en primer lugar, a todas las acciones tendentes a respetar positivamente y a expresar la dignidad humana. No se refiere a la dignidad de cargos o al estatus económico o político, ni siquiera a la dignidad moral, sino a la dignidad absoluta de todo ser humano por serlo, en el doble sentido de reconocerla en los demás y de vivir uno mismo desde ella. El reconocimiento de la dignidad humana entraña el reconocimiento de que en el ser humano hay algo de incondicionado, o, dicho en términos bíblicos, es imagen de Dios. El reconocimiento de la dignidad humana es así, en definitiva, reconocimiento de Dios mismo, que no solo nos ha creado, sino que, precisamente, nos ha creado en Cristo para hacernos participar en él de su misma vida divina. 
La unión fraterna es un paso más concreto en ese reconocimiento, ya que el Dios reconocido en el ser humano se decanta como Padre materno y, por lo tanto, los seres humanos son reconocidos, precisamente, como hermanos. Así, buscar de manera concreta y efectiva la fraternidad universal, es reconocer al Dios cristiano, que crea esos vínculos obligantes entre todos sin excepción, al hacerse Jesús, el Hijo único y eterno de Dios, nuestro Hermano, el Hermano universal.

El bien de la libertad comprende para el concilio la libertad democrática, en el sentido más fuerte de la palabra. Pero no se restringe a ella, ni a la libertad moral, en el sentido de libertad de coacción en la vida civil. Abarca, sobre todo, el proceso exigente y hermoso de liberar la libertad de todo lo que la mantiene esclava o enferma, de todo apetito desordenado. En primer lugar, del amor propio, es decir, de pulsiones, deseos o quereres autonomizados del resto del ser y absolutizados, que se imponen sobre lo que brota de lo más genuino, del fondo del corazón, del manantial del querer y del obrar.

Así, pues, el ser humano es sagrado, y de él, movido por el Espíritu, brota vida eterna. En las realizaciones históricas, cuando son realmente humanizadoras, se da, más allá de su propia materialidad, lo definitivo, lo que trasciende la transitoriedad típica de lo humano. Hasta ahí llega el concilio.

En suma, el concilio valora las instituciones y las estructuras que posibilitan la vida humana y pide que se potencien y se superen las que dificultan ese desarrollo propiamente humano. Pero sostiene que lo estrictamente escatológico son las acciones humanas, emprendidas para lograrlo, en cuanto no son acciones meramente técnicas u organizativas, sino que contienen ese respeto positivo y concreto por la dignidad humana y fomentan lazos de fraternidad, en cualquier modalidad de relación, y lo hacen liberando su libertad y ayudando a que otros liberen las suyas.

\subsection{Responsabilidad hacia sus hermanos y ante la historia}

A continuación, exponemos esta novedad histórica de la espiritualidad conciliar, el centro de nuestra tesis, desde otro armónico, equivalente para el concilio a la historia, que es la cultura. El colofón del n. 55 de Gaudium et spes, que pertenece al capítulo sobre "El sano fomento del progreso cultural", declara que "somos testigos de que nace un nuevo humanismo, en el que el ser humano queda definido principalmente por su responsabilidad hacia sus hermanos y ante la historia".

Existe equivalencia entre la noción de cultura empleada por el concilio y la de historia que hemos manejado nosotros. Según el concilio, cultura es

... todo aquello con lo que el ser humano afina y desarrolla sus innumerables cualidades espirituales y corporales; procura someter al mismo orbe terrestre con su conocimiento y trabajo; hace más humana la vida social, tanto en la familia 
como en toda la sociedad civil, mediante el progreso de las costumbres e instituciones; finalmente a través del tiempo formula, comunica y conserva en sus obras grandes experiencias espirituales y aspiraciones para que sirvan de provecho a muchos; más aún, a todo el género humano. De ahí que la cultura humana lleve consigo necesariamente un aspecto histórico y social ${ }^{18}$.

De acuerdo con el concilio, el sujeto de la cultura es el ser humano como colectividad personalizada. Y los contenidos son el desarrollo de sus cualidades, la transformación de la tierra, la humanización de la sociedad, comenzando por la familia, y los monumentos de esta experiencia humana colectiva, que constituyen las expresiones culturales, en el sentido convencional de la palabra. El desarrollo de cualidades y la transformación de la tierra, mediante la ciencia y la técnica, se refieren a lo que hemos calificado de relativa positividad, porque potencia al ser humano y a la humanidad como cuerpo. El aumento de calidad humana tiene que ver con lo que hemos calificado de definitivo en esta historia.

Pero no es solo que de hecho el ser humano sea el sujeto de la cultura, sino que cada día toma más conciencia de su carácter de tal.

Cada día es mayor el número de hombres y mujeres, de cualquier grupo o nación, que tienen conciencia de que son ellos los autores y promotores de la cultura de su comunidad. En todo el mundo crece más y más el sentido de la autonomía y, al mismo tiempo, de la responsabilidad, lo cual tiene enorme importancia en pro de la madurez espiritual y moral del género humano. Esto se ve más claro si fijamos la mirada en la unificación del mundo y en la tarea, que nos ha sido impuesta, de edificar un mundo mejor en la verdad y en la justicia ${ }^{19}$.

Así, pues, el ser humano es el verdadero autor y no solo el actor, que ejecuta un libreto escrito de antemano, sea en su constitución natural, sea por Dios, ni es mero agente que hace lo que le mandan o, más generalmente, lo establecido. Ahora bien, el ámbito de su acción no es solo la propia persona, sino que también la comunidad humana a la cual pertenece. Pero este carácter de autor no es autárquico, ya que a la autonomía va aparejada de la responsabilidad. El ser humano debe responder ante Dios, que no es su Amo, sino quien lo ha creado creador para que perfeccione y humanice la naturaleza. Más todavía, para entablar con él un diálogo vivo, en el cual él tiene la primera palabra y lo propio del ser humano es responder, desde su autonomía. En ese diálogo, Dios no pide nada para sí, sino que encarga a cada ser humano de sus hermanos para que juntos, viviendo en respectividad positiva, edifiquen un mundo mejor que el que han encontrado, basado en la verdad, es decir, en la realidad de las cosas y en la conciencia recta

18. GS 53.

19. GS 55 . 
de sí mismos, y en la justicia, es decir, en el respeto positivo de los derechos de todos, desde la asunción de los correspondientes deberes.

Elegir este modo de vida y vivirlo consecuentemente es decisivo para la madurez espiritual y moral del género humano. Podemos decir que en eso consiste el quicio de la espiritualidad conciliar. En esto consiste el nuevo humanismo, caracterizado por la responsabilidad de cada ser humano hacia sus hermanos y ante la historia. Así lo decía Pablo VI en el discurso de apertura de la última sesión conciliar: "Aquí en esta asamblea, la manifestación de dicha ley de la caridad tiene un nombre sagrado y grave: se denomina responsabilidad [...] Nosotros nos sentimos responsables de toda la humanidad" ${ }^{20}$.

La espiritualidad del concilio subraya que el amor a Dios y al prójimo, el núcleo trascendente alrededor del cual gira todo el cristianismo y en el que se juega la humanidad del ser humano, en este momento de nuestra historia, se traduce como responsabilidad. La responsabilidad primaria ante Dios se expresa como responsabilidad hacia el ser humano concreto con el cual convivo y como responsabilidad hacia la historia para superar lo que traba el proceso de humanización cualitativa o lo que positivamente deshumaniza, y para echar adelante lo que contiene humanidad cualitativa.

\section{La contribución de la Iglesia}

Si esta vocación es común a toda la humanidad, el concilio se pregunta cuál es la contribución de la Iglesia, es decir, de los cristianos, a la realización de este designio. Responde que la Iglesia está para contribuir a la humanización de la humanidad con lo que tenemos como cristianos, que es la fe en el Dios y Padre de nuestro Señor Jesucristo, que nos ha creado para que seamos hijos en su Hijo, que es Jesús de Nazaret, paradigma de humanidad que nos atrae con su prestancia, y el Espíritu que él derramó sobre toda carne para que, siguiendo su impulso, caminemos hacia la fraternidad de las hijas e hijos de Dios.

La fe en Dios aporta un horizonte y un destino para toda la humanidad, una confianza de fondo en la realidad y una esperanza común para la historia. La propuesta de Jesús apunta a una humanidad cualitativa: todos somos humanos, formamos parte de la única humanidad, pero, sobre todo, estamos llamados a constituirnos en humanos, a humanizarnos. Esa humanidad a la que somos llamados ya existe, es futuro para nosotros y nos atrae hacia él. Es Jesús de Nazaret, en quien el ser humano supera infinitamente al ser humano ${ }^{21}$. El Espíritu posibilita: todos tenemos dentro esa misma fuerza, que nos capacita para huma-

20. "El amor, cifra del concilio", n. 16.

21. "Sabed que el ser humano supera infinitamente al ser humano y escuchad, de vuestro maestro, vuestra verdadera condición que ignoráis. Escuchad a Dios". B. Pascal, Pensamientos 131 (Madrid: Alianza Editorial, 1981, p. 54); P. Trigo, "Jesús, para- 
nizarnos, según el paradigma de Jesús, es decir, para vivir con confianza y, desde esa confianza de fondo, instaurar una reciprocidad de dones. Todos podemos recibir agradecidos la vida y desde esa actitud crear, junto con los demás, un mundo con más posibilidades y más humano.

Este aporte de los cristianos se da desde nuestra pertenencia a la única humanidad, es decir, solo se da en el acto de cargar solidariamente con la historia. No se da desde fuera de ella. Si unos especialistas en cristianismo transmitieran esta doctrina sin que los demás los reconocieran como compañeros de su misma aventura y de su misma suerte, aunque los contenidos fueran exactos, no estarían transmitiendo el mensaje evangélico, ya que el modo de transmitirlo desdice lo que verbalmente dicen. El problema no es meramente la falta de congruencia. Si solo fuera eso, no habría contradicción, ya que otros pueden captar el mensaje, a pesar de los mensajeros. El problema es que la verdad cristiana es praxis, se hace; no es un sentido que se posee, independientemente de la realidad, y que se proyecta sobre ella, sino el sentido que va naciendo al transformarla superadoramente y plenificarla. Dicho en lenguaje del cuarto evangelio, es "la luz de la vida" (Jn 8,12). Primero se vive como una apuesta de fe, y, en la medida que se va viviendo, se va viendo el sentido que tiene esa vida ${ }^{22}$. El sentido es, pues, el de ese modo de vivir.

Jesús no se limita a hablar de Dios. Él es su sacramento. No solo su mensajero, sino su presencia. Él es "Dios-con-nosotros". Su solidaridad hace verdad, actualiza y realiza la alianza incondicional de Dios con nosotros. De igual modo, los cristianos no solo aludimos a este misterio de Dios, sino que lo hacemos presente con la fuerza del Espíritu. Por lo tanto, los cristianos, solo desde la encarnación solidaria en la única historia, podemos dar nuestro aporte a la humanidad. Solo desde esa apuesta vital cobra significado, sentido y densidad ese mensaje.

Más aún, esta solidaridad no acontece desde la posesión de alguna ventaja adicional, de un "suplemento del alma", que nos haga superiores al resto de los mortales. Así como Jesús se hizo "uno de tantos", más todavía, "asumió la condición de esclavo", hasta afrontar desarmadamente la muerte reservada a ellos, también los cristianos nos solidarizamos desde sentir lo que sienten nuestros contemporáneos, desde los mismos impulsos a ponernos a la altura del avance científico-técnico, participando de este proceso desde nuestras capacidades y posibilidades y buscando incrementarlas incesantemente, hasta la misma necesidad de seguridad y reconocimiento y la misma angustia por nuestro futuro, desde la soledad de nuestro ser individual. Llevamos, pues, nuestro tesoro en vasos de barro y enriquecemos desde nuestra pobreza.

digma absoluto de humanidad", en Jesucristo, prototipo de humanidad en América

Latina (México: Obra Nacional de la Buena Prensa, 2000, pp. 85-128).

22. Como dice un dístico: "Ciego sigo la voz y me nacen ojos". 


\subsection{Responsabilidad histórica desde la simpatía y la compasión}

Así, pues, la novedad conciliar está en poner la realización cristiana en la responsabilidad histórica. Esto tiene dos dimensiones. La primera es encarnarse en la humanidad, optar solidariamente por ella, descartar una salvación individualista o corporativa y ligar nuestra suerte a la de toda la humanidad, contribuyendo a su humanización, desde nuestras capacidades y posibilidades. La segunda es aportar nuestra especificidad cristiana: ese Dios en quien apoyar confiadamente la vida, Jesús de Nazaret como paradigma de humanidad para seguirlo y salir a su encuentro, y el Espíritu de hijos y hermanos a quien discernir para secundar su impulso en uno y en los signos de los tiempos.

El talante de esta espiritualidad conciliar viene dado por dos armónicos: la simpatía y la compasión. Como se sabe, los dos términos significan lo mismo: son la misma palabra, proveniente la primera del griego y la segunda del latín. Lo común a ambas expresiones es el ser afectados por otros y afectarse con ellos. Lo primero es, pues, la intromisión de los demás en uno. Ese vivir estructuralmente abiertos a la naturaleza y a los seres humanos, de modo que nuestra vida no nazca solo de nosotros, sino que sea también una respuesta a la impresión que ellos dejan en nosotros, cuando nosotros vivimos con la puerta abierta. Es acoger esa vida suya en nosotros y ponerse a tono con ella. Así decía Pablo que se hacía todo a todos, sabio con los sabios, sencillo con los ignorantes y hasta enfermo con los enfermos.

Es lo que expresa el texto más sintomático del concilio con el cual se abre la Constitución sobre la Iglesia en el mundo actual: "Los gozos y las esperanzas, las tristezas y las angustias de los seres humanos de nuestro tiempo, sobre todo, de los pobres y de cuantos sufren, son también gozos y esperanzas, tristezas y angustias de los discípulos de Cristo. Nada hay verdaderamente humano que no resuene en su corazón". Como se ve, el texto recoge los dos armónicos: tanto la capacidad de sintonizar con las afecciones más positivas de los demás, y por eso de despertarlas en ellos respecto de uno mismo, como la de concordar con sus padecimientos, de manera que se sientan acompañados. Ese vivir con los demás en las buenas y en las malas es el núcleo del talante de la espiritualidad del concilio.

Y no hace falta gastar mucha tinta en probar que ese mismo era el talante de Jesús, que despertaba una simpatía inmensa por donde pasaba, y que era también entrañablemente querido por su capacidad de conmoverse ante el dolor de los sufrientes y necesitados y de darles compañía, confortarlos y ayudarlos.

La simpatía y la compasión son para Jesús y para el concilio actitudes básicas, radicales, absolutas. No son medios para obtener otros fines, ni están condicionadas por las cualidades o la actitud de los demás. Esta apertura incondicional y concreta a los demás es expresión elemental de amor, es solidaridad básica. Este es el contenido de la palabra encarnación, que estuvo tan 
en boga en tiempos del concilio y que expresa muy adecuadamente, tanto el misterio de Jesús como la posición vital y el tono anímico de sus seguidores con la responsabilidad que entraña.

\subsection{Cultivo de la interioridad: ejercicio de la autonomía responsable}

Ahora bien, la encarnación en esta humanidad histórica posibilita el discernimiento, pero también lo exige, porque en la historia se dan la gracia y el pecado, la humanización y la deshumanización, la inclinación al bien y la tentación; y se dan mezcladas, más aún, encubiertas, ya que no pocas veces lo que se propone como lo mejor no lo es tanto, incluso está mezclado de mal o hasta es fundamentalmente malo, pero publicitado como bueno. Y lo que se presenta como poco atractivo, incluso como carente de interés y hasta como positivamente desechable, es, no pocas veces, lo que encierra más potencialidades humanizadoras. Por eso, porque vivimos en una situación de pecado, el camino que lleva a la perdición se presenta como ancho y gustoso, mientras que la senda que conduce a la vida está escondida y parece poco transitable y poco frecuentada ${ }^{23}$.

Así, pues, la responsabilidad exige discernimiento; pero el discernimiento exige, a su vez, una relativa trascendencia respecto de lo establecido, exige ser persona y no limitarse a desempeñarse como miembro de los conjuntos en los que se está implicado. Requiere, insiste el concilio, el cultivo de la interioridad. Sin interioridad no hay encarnación, sino mera adaptación a lo dado, lo que excluye la solidaridad. Como también podríamos decir, a la inversa, que la interioridad sin encarnación no contiene trascendencia, no llega a asumir la realidad, ni siquiera la propia, sino que se reduce a mero ensimismamiento, solipsismo extraviado.

El ser humano, "por su interioridad es, en efecto, superior al universo entero; a estas profundidades retorna cuando entra dentro de su corazón, donde Dios le aguarda, escrutador de los corazones, y donde él personalmente, bajo la mirada de Dios, decide su propio destino" 24 .

El corazón, en sentido bíblico, no es meramente la sede de los sentimientos, sino la raíz de lo propiamente humano, donde se originan las acciones que definen al ser humano, que lo humanizan o deshumanizan. Pues bien, se da la interiorización cuando el ser humano se mueve más adentro que sus pulsiones o sentimientos, más adentro que filias o fobias, y sin dejarse coaccionar por presiones ambientales, cuando decide con autonomía y desde su realidad verdadera y en la realidad en la que consiste. Cuando llega a ese nivel, el ser humano se encuentra ante Dios, le dé o no ese nombre. De hecho, se encuentra ante la 
Presencia indisponible y agraciadora. Si actúa con libertad liberada, o dicho de otra manera, responsablemente, su acción lo humaniza.

El concilio insiste en que esta autonomía nada tiene de autárquica, sino que, como hemos insistido, es responsable. Esto lo explana bajo el concepto de la ley moral, que es, más que concepto, símbolo, y de este modo hay que verlo para no caer en malentendidos:

En lo más profundo de su conciencia descubre el ser humano la existencia de una ley que él no se dicta a sí mismo, pero a la cual debe obedecer y cuya voz resuena, cuando es necesario, en los oídos de su corazón, advirtiéndole que debe amar y practicar el bien y que debe evitar el mal: haz esto, evita aquello. Porque el ser humano tiene una ley escrita en su corazón, en cuya obediencia consiste la dignidad humana y por la cual será juzgado personalmente. La conciencia es el núcleo más secreto y el sagrario del ser humano, en el cual éste se siente a solas con Dios, cuya voz resuena en el recinto más íntimo de aquélla. Es la conciencia la que de modo admirable da a conocer esa ley, cuyo cumplimiento consiste en el amor de Dios y del prójimo. La fidelidad a esta conciencia une a los cristianos con los demás seres humanos para buscar la verdad y resolver con acierto los numerosos problemas morales que se presentan al individuo y a la sociedad ${ }^{25}$.

Este texto da en la médula de la espiritualidad conciliar, pero tiene el inconveniente de siglos de malentendidos, porque la ley a la que se refiere no es ningún código objetivado, ni es heterónoma. El concilio afirma, por el contrario, taxativamente la autonomía de la conciencia. Es parte inalienable de la dignidad del ser humano, que hasta Dios respeta, o mejor dicho, que al menos Dios respeta siempre. Es, ciertamente, trascendente, pero por inmanencia. En ese sentido, el concilio habla (siguiendo a Pablo en 1 Cor 6,19) de sagrario, o santuario. La grandeza del ser humano es que lo habita la trascendencia. Y que esta trascendencia juega, hablando humanamente, a favor nuestro. Dios no está casado con la ley, sino con nosotros. Ahora bien, nosotros hemos sido creados buenos y para el bien, que nos excede infinitamente. Por eso, decíamos que cuando elegimos desde lo que somos y en el seno de la realidad en la que consistimos, elegimos desde la libertad liberada y nos humanizamos.

El concilio habla de obediencia, y dice bien, porque en el santuario de la conciencia se da la alteridad; pero a su vez, esa alteridad da la medida de lo que somos, porque nos trasciende por inmanencia. Nos habita, no como un huésped, sino religándonos a la realidad y, en ese sentido, posibilitando nuestra existencia. Por eso, esa interioridad suma nos conecta con los demás, de manera que exis- 
timos no aherrojados, en el vacío, sino consistiendo con los demás en la realidad. Esa es la fuente de nuestra consistencia.

Hemos insistido en este punto porque el nuevo humanismo al que se refiere la espiritualidad conciliar, que consiste en la responsabilidad hacia el hermano y ante la historia, es absolutamente imposible e incluso impensable sin el ejercicio denodado de esta interioridad. Sin ella, nos queda grande, nos resulta desmedido para nuestra condición de meros individuos y meros miembros del conjunto. Lo contrario del individualismo es el comunitarismo o el colectivismo, o el corporativismo, tres versiones del otro polo no superador. Al individualismo solo se lo supera desde un crecimiento exponencial de la persona, en el sentido en que hemos insistido. Solo ese individuo repotenciado y trascendido es capaz de vivir históricamente, de responsabilizarse de la historia, desde la encarnación solidaria en ella.

\section{El cultivo de la sabiduría para una humanidad más cualitativa}

El concilio se refiere a otro armónico de este robustecimiento trascendente del ser humano para que pueda asumir su responsabilidad epocal. Es el cultivo de la sabiduría,

.. la cual atrae con suavidad la mente del ser humano a la búsqueda y al amor de la verdad y del bien. Imbuido por ella el ser humano se alza por medio de lo visible hacia lo invisible. Nuestra época, más que ninguna otra, tiene necesidad de esta sabiduría para humanizar todos los nuevos descubrimientos de la humanidad. El destino futuro del mundo corre peligro si no se forman seres humanos más instruidos en esta sabiduría. Debe advertirse, a este respecto, que muchas naciones, económicamente pobres, pero ricas en esta sabiduría, pueden ofrecer a las demás una extraordinaria aportación ${ }^{26}$.

Es claro que esta sabiduría a la que se refiere el concilio no puede adquirirse mediante un aprendizaje objetual, y en ese sentido descomprometido, como se adquieren las ciencias. También en este caso, como en el de la conciencia moral, se da la alteridad trascendente, a la cual hay que abrirse con amor deseoso (eso significa literalmente filosofía, y hacia ahí apunta, por ejemplo, el sentido socrático), humilde y limpio. Es una actitud integral de la persona, que impide que se totalice, que la lleve más allá de sí, a lo que la trasciende y la colma.

La sabiduría no se presenta como un imperativo moral. No apela a ningún deber ser. Se presenta invitando y atrayendo, apela a nuestro deseo y, específicamente, a nuestro deseo de humanidad verdadera y plena, una humanidad que no se logra con la satisfacción que da la posesión de bienes, ni el éxito económico, social o político, ni siquiera la autorrealización. La sabiduría es rigurosamente trascendente, como lo es el propio ser humano. Por eso, la sabiduría lo invita

26. GS 15 . 
a no conformarse con lo subalterno, ni confinarse en ello, sino a aspirar a lo verdadero, a lo que es real y a realizarse, entrañándose en la realidad y llevándola a dar de sí. La sabiduría aspira a la realidad verdadera que, como tal, es buena y realmente apetecible, hermosa. Por eso, dejarse llevar por el amor a la sabiduría es una actitud realmente humanizadora, un don altísimo y, a la vez, la decisión humana más liberadora.

El concilio apunta con agudeza que, sin esta actitud, la actitud investigativa que busca dominar, que se centra en los medios, descuidando los fines, puede resultar catastrófica. Por eso, insiste en que hoy, que esa actitud investigativa se ha desarrollado tan exponencialmente, como nunca en la historia conocida, es más necesario que nunca el cultivo apasionado de la sabiduría. Sin ella, la historia marcha a la catástrofe. Hoy, que ya se hace evidente la ruptura del equilibrio ecológico y empiezan a preludiarse signos de esa catástrofe, es más evidente que en tiempos del concilio la necesidad de cultivar humilde y denodadamente esa sabiduría. Y, sin embargo, es patente que está completamente ausente del orden establecido, incluso negada por él, que se ha puesto positivamente de espalda a ella, aunque no pocas mujeres y hombres la cultiven de manera exquisita y se sientan alegres de hacerlo, aun tan a contracorriente.

Sorprendentemente, el concilio, oteando veneros en los que podamos beber esa sabiduría tan imprescindible, nos lleva a dirigir nuestra atención a los pueblos pobres, pobres, dice, en bienes económicos, pero ricos en esa sabiduría trascendente. Nos parece una muestra muy preclara de la trascendencia del concilio, que, en una época en la cual la parte más progresista del occidente desarrollado, principal artífice del concilio, se sentía tan legítimamente contenta con la dirección que le estaba dando a la sociedad para superar lo que había conducido a la conflagración mundial, tuviera, sin embargo, ojos para ver lo que le estaba haciendo falta y para verlo en los pueblos subdesarrollados, que en su deseo eran vistos como en vías de desarrollo y necesitados, por eso, de su ayuda. En este punto crucial, el concilio pensó, con razón, que el occidente era el necesitado que debía acudir a esa fuente cualitativa.

Creemos que este punto es hoy más evidente y necesario que en tiempos del concilio porque, a diferencia de esa época, el occidente vive hoy una fase terriblemente regresiva, aunque, por eso mismo, no pocos en él, sí se desmarcan y buscan otros caminos. También en el tercer mundo y, más en concreto, en nuestra América, las élites occidentalizadas viven una fase regresiva y, por eso mismo, en nuestro caso es perentorio dirigirnos en busca de sabiduría a nuestros pueblos e, incluso, a los pobres de nuestros pueblos. A diferencia de las élites, las culturas populares de nuestra América (indígena, afrolatinoamericana, campesina y suburbana) están en efervescencia, tanto que están provocando el nacimiento de la tercera época de nuestra América, que estaría caracterizada por el reco- 
nocimiento de su carácter multiétnico y pluricultural, en un estado de justicia e interacción simbiótica ${ }^{27}$.

Concretamente para los cristianos, la participación en las comunidades eclesiales de base es una ocasión única para beber esta sabiduría, pero con el precio de entrar en la casa del pueblo.

\subsection{Historia escatológica y escatología transhistórica}

Esta entrega a hacer la historia, formando un cuerpo social con nuestros contemporáneos, no disminuye en nada la tensión escatológica característica de Jesús y de los mejores momentos del cristianismo. Pero nuestra entrega indivisa a la comunidad divina no nos aparta de este mundo y de esta historia, no nos lleva a desinteresarnos de esta tierra, ni de la suerte de nuestros contemporáneos, porque somos capaces de contemplar el designio de Dios, que incluye a la creación y en ella a la historia, transfiguradas por fin, llenas de su gloria, de la gloria de los hijos de Dios. Porque hemos contemplado que ese designio se realiza encarnándose en esta humanidad y asumiéndola históricamente de modo que ya para toda la eternidad uno de la comunidad divina es también uno de la comunidad humana, su primicia, su primogénito. Porque hemos contemplado que ni el pecado, ni el rechazo, que se consuma en el asesinato de su Hijo querido, han podido apagar el amor de Dios, su designio de hacernos hijos en él, como tampoco ha secado el compromiso de Jesús con nosotros, sino que, por el contrario, lo consuma: él es el que se entrega por nosotros hasta la muerte. El pecado no lleva al juicio de condenación sobre los pecadores, no logra romper el designio de salvación universal: Dios es capaz de sacar bien del mal y el amor creador de Dios rehabilita realmente al pecador.

Dios no es el Dios de los separados del mal y de los que lo cometen, el Dios de los que se desolidarizan de la humanidad que emplea mal su condición de adulta. Su divinidad se juega, por el contrario, en la apuesta por la rehabilitación. El concilio nos anima a contemplar el Espíritu de Dios, que es el mismo de Jesús, empujando la historia hacia el perdón, la reconciliación, la solidaridad, hacia la humanización, que no puede ser sino tendencialmente de todos para que lo sea de verdad.

Por todo esto es la fe en el Dios y Padre de nuestro Señor Jesucristo la que envía a esta misión y da libertad para ella, es Jesús el que da el perfil humano concreto y es el Espíritu el que la posibilita. La entrega a la comunidad divina, que se realiza, cómo no, al ponerse en manos del Padre, al contemplar a Jesús y seguirlo, y al obedecer al Espíritu, desemboca en el compromiso solidario

27. P. Trigo, Cómo relacionarnos humanizadoramente (Caracas: Gumilla, 2012, pp. 195-224). 
por humanizar la tierra, la sociedad y el ser humano, partiendo del trabajo por hacerlo con nosotros mismos.

Si contemplamos al ser humano 3/4al ser humano que somos nosotros mismos y a los seres humanos contemporáneos $3 / 4$ desde el designio de Dios realizado plenamente en Jesús, la vida adquiere un diseño unitario: ser humano entre seres humanos. Pero en el entendido de que ser humano no es ser un individuo que entabla relaciones según sus preferencias, ni un ser marcado por su pertenencia a la sociedad de los productores y, en esa medida, de los consumidores, sino un ser puesto en la vida por otros seres humanos como fruto de su amor, un ser que se levanta en una familia, en una tierra, en una cultura, en una historia, un ser que recibe estructuralmente la vida de Dios, un ser a quien Jesús de Nazaret ha hecho su hermano, llevándolo solidariamente y entregándole su mismo Espíritu de hijo de Dios, un ser llamado a responder libre y creativamente desde esos haberes, correspondiendo a esas relaciones constituyentes y abriéndose desde ellas responsablemente a toda la humanidad y a la creación, y, en concreto, a la tierra que la soporta.

El concilio nos propone vivir este humanismo integral, el de Jesús de Nazaret, desde nuestra realidad y desde la conducción del Espíritu que, moviéndonos, nos da fuerza y dirección. En una época en que otros viven su humanidad de modo individualista o en comunidades cerradas, sin una religación trascendente o relacionándose con ella desde otros semblantes, nuestro modo de constituirnos en humanos puede parecer dicotómico, repartido entre la tierra y el cielo, para decirlo de un modo gráfico y provocativo.

En nosotros está ser el evangelio viviente de esa humanidad que despliega su vida en la presencia de Dios, posibilitada por la inmanencia trascendente de Dios, humanizado en Jesús y moviéndonos por su Espíritu, desde más adentro de lo íntimo de nosotros mismos. No es plenamente humano el que vive ensimismado o disperso y no es capaz de percibir ese movimiento en su ser. Vivir atentos, recogidos, en lo que se está, haciendo justicia a la realidad y a la trascendencia que en ella se agita, y secundándola, es ponerse en camino de humanización.

No es plenamente humano el que desconoce los lazos que lo constituyen antes de cualquier decisión suya, relaciones que lo hacen concreto y que piden responsabilizarse. Tampoco lo es el que absolutiza los lazos de familia, pueblo, cultura, empresa, afiliación política, restringiendo a ellos la humanidad que le incumbe. Tampoco es humano el que habita un universo lleno, el que no es capaz de situarse ante la exterioridad de la realidad, ante la nada, y ante la fuente sellada de la vida, que nos religa a ella y, en definitiva, a él.

Todo esto, nosotros los cristianos lo hemos recibido y lo vivimos desde la historia viva de Jesús de Nazaret, un ser humano que vivió en esta tierra hace veinte siglos, que murió torturado y que ahora, resucitado por Dios y puesto por 
él como arquetipo de humanidad, nos atrae con su prestancia desde la casa de Dios. A través de la comunidad histórica de sus discípulos, hemos recibido este humanísimo tesoro divino, que nos esforzamos por hacer vida y compartir.

\subsection{Seguimiento a Jesús y responsabilidad por la historia}

Por eso, todo lo dicho sobre la encarnación en la humanidad histórica, una encarnación responsable desde la simpatía y la compasión, todo lo dicho sobre el fomento de la interioridad, la obediencia a la voz de la conciencia y el cultivo de la sabiduría, toma un perfil muy concreto para los cristianos: el seguimiento de Jesús de Nazaret con su mismo Espíritu. No es que el seguimiento lo sustituya, por eso no sobra nada de lo dicho, sino que ha de ser tenido siempre muy en cuenta. Pero es que todo eso lo vemos realizado paradigmáticamente en Jesús de Nazaret, no solo en el sentido textual de que Jesús sea un ejemplo sobresaliente, y por eso realmente ejemplar, de ese modo humano de vivir, sino en el más preciso de que él es el prototipo de humanidad, es decir, la Imagen perfecta de Dios, a cuya imagen hemos sido creados los seres humanos; para decirlo gráficamente, el molde en el que hemos sido fabricados. Y, más todavía, en el sentido de que él es el arquetipo de humanidad: él es principio de humanidad, de él brota humanidad, él es el que, atrayéndonos desde el seno del Padre, nos humaniza, si secundamos su atracción.

Por eso, la espiritualidad conciliar se decanta como seguimiento de Jesús. Si el ser humano no fuera histórico, seguir a Jesús sería lo mismo que imitarlo. Pero, como el ser humano es histórico y la historia contiene novedades, seguir a Jesús no puede consistir en hacer lo mismo que él, sino en hacer en nuestra situación lo equivalente a lo que él hizo en la suya, ya que su época y su situación concreta son distintas de las nuestras.

Por eso, la obra más característica de la espiritualidad preconciliar se llama La imitación de Cristo. Y por eso, fuera de las épocas de reforma no disciplinar, como el comienzo del siglo XIII o el del XVI, los evangelios no desempeñaron un papel central. Por eso, también hoy, como un síntoma fehaciente de que no se quiere recibir el concilio, vuelve la relación pietista con Jesús, a través de la adoración al Santísimo y de otras devociones de tipo entusiástico, dejando de lado la contemplación de los evangelios como la fuente de la espiritualidad. No es tampoco casual que quienes las practican no se caractericen por su empeño en responsabilizarse de la historia.

Y refiriéndonos a nuestra América, no es casual que hoy la contemplación de los evangelios, en orden al seguimiento, y la responsabilidad con la historia no den la pauta de nuestro cristianismo, a pesar de las declaraciones de los documentos oficiales que para la mayoría de los que los aprueban, en gran medida, son solo saludos a la bandera. Como Iglesia, hoy vivimos dando la espalda a lo que se vivió en los años setenta y ochenta, cuando la fidelidad a este seguimiento condujo, como es inevitable, a la participación de su pasión. Hoy, la negativa a 
responsabilizarnos de la historia, tan patente en nuestra Iglesia, va de la mano con el abandono del seguimiento de Jesús de Nazaret, sustituido por Cristos más devotos y cómodos, hechos a nuestra medida, que entusiasman, pero no incomodan ni, menos aún, urgen al seguimiento. Sin embargo, la buena nueva de nuestra Iglesia, verdadero kairós para ella y para el mundo, es la figura del papa Francisco, que nos insta a vivir desde la contemplación diaria y discipular de los santos evangelios y que nos da el ejemplo de esta vida responsable del hermano y de la historia, desde la simpatía y la compasión. Un cristiano, además, salido de nuestra América.

Por eso, urge proponer como buena nueva la espiritualidad conciliar, que caracterizó a nuestra Iglesia latinoamericana en esas décadas en que el cristianismo fue, como lo fue Jesús, una bandera discutida, signo de esperanza y alegría para nuestros pueblos oprimidos y creyentes y para los solidarizados con ellos, y motivo de escándalo y objeto de persecución para los responsables de esa situación. Si no reponemos esta espiritualidad jesuánica, seremos como la sal que ha perdido el sabor y no sirve ya para nada.

Ahora bien, lo que hemos expresado no ha salido de un escritorio, sino de una vivencia eclesial, y no de una vivencia excepcional, sino de una vivencia compartida, que sigue siendo significativa en nuestra Iglesia, aunque sea minoritaria. Y, además, aunque minoritaria, ciertamente en comunión con el resto de los cristianos y, en particular, con la institución eclesiástica. Sobre todo hoy, cuando el papa Francisco actúa de manera tan creativa y convincente, está la responsabilidad con el hermano y con la historia, a través de tantos gestos tan expresivos, tan contraculturales y tan henchidos de amor del bueno, y a través de denuncias tan clamorosas e irrefutables y de propuestas tan convincentes y superadoras.

Queremos confesar agradecidos, para concluir, que una fuente generosa de nuestra pobre vivencia de esta espiritualidad está en los pobres con espíritu con los que comparto mi fe, mi amor fraterno y mi vida cristiana. Ellos me comunican su encarnación solidaria, su simpatía y compasión, su interioridad, llena de paz, en medio de tantas angustias, y su sabiduría, realmente espiritual. Todo ello, en medio de una gran debilidad y de tensiones constantes que parecen por momentos inmanejables. Ellos, como Pablo, experimentan que cuando son débiles son fuertes, porque la gracia actúa en la debilidad. Por eso, ellos, como Jesús, nos enriquecen con su pobreza. 